\title{
Widening of the safe trajectory range during subaxial cervical pedicle screw placement: advantages of a curved pedicle probe and laterally located starting point without creating a funnel-shaped hole
}

\author{
Subum Lee, MD, ${ }^{1}$ Junghan Seo, MD,1 Moon Kyu Lee, MD, ${ }^{2}$ Sang Ryong Jeon, MD, PhD, ${ }^{1}$

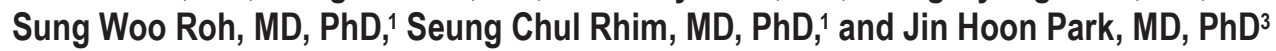

1Department of Neurological Surgery, Asan Medical Center, University of Ulsan College of Medicine, Seoul; and Departments of ${ }^{2}$ Neurology and ${ }^{3}$ Neurological Surgery, Gangneung Asan Hospital, University of Ulsan College of Medicine, Gangneung, Korea

OBJECTIVE The small diameter of cervical pedicles and a large transverse cervical pedicle angle are challenges that have led spinal surgeons to investigate how they could achieve a wider safety trajectory and reduce the insertion angle during cervical pedicle screw (CPS) placement. In this paper, the authors detail the advantages of using a curved pedicle probe and a laterally located entry point for overcoming these challenges.

METHODS From March 2012 to May 2016, the authors performed posterior cervical fusions using CPSs on 119 consecutive patients. The lateral mass screw conversion and the CPS breach rate were analyzed. Using preoperative CT, it was determined that $\theta_{\text {lat }}$ is similar to the anatomical pedicle angle, and $\theta_{\text {med }}$ is the minimally acceptable medial angle. The actual insertion medial angle $\left(\theta_{\text {ins }}\right)$ was determined by postoperative CT. To identify how much of the medial angle on $\theta_{\text {ins }}$ could be reduced from the anatomical pedicle angle $\left(\theta_{\text {lat }}\right)$, and how much closer to $\theta_{\text {med }},\left(\theta_{\text {ins }}-\theta_{\text {med }}\right) /\left(\theta_{\text {lat }}-\theta_{\text {med }}\right)$ was calculated. To verify shifting of the entry point and widening of the trajectory, the mean df/Df (i.e., shifted facet point/ planned facet point) values were analyzed.

RESULTS The total number of planed CPSs was 759 , the conversion rate was $4.61 \%(35 / 759)$, and the accuracy rate was $95.9 \%$ (694/724). The authors could calculate that $\theta_{\text {ins }}$ could be expected near the $90 \%, 80 \%, 80 \%, 80 \%$, and $110 \%$ value of $\theta_{\text {lat }}$ on C-3, C-4, C-5, C-6, and C-7 levels, respectively, with the $\left(\theta_{\text {ins }}-\theta_{\text {med }}\right) /\left(\theta_{\text {lat }}-\theta_{\text {med }}\right)$ equation. The mean df/Df values were $0.64,0.62,0.63,0.63$, and 1.24 on the $\mathrm{C} 3-7$ levels, respectively.

CONCLUSIONS Through the use of a curved pedicle probe and a laterally located starting point, the planned and laterally located entry point medial shift was made during CPS placement. The entry point shift yielded a wider, safe trajectory and reduced the burden of making a large medial angle, similar to an anatomical cervical pedicle lateral angle, for safe CPS placement without creating a funnel-shaped hole.

https://thejns.org/doi/abs/10.3171/2016.12.SPINE16738

KEY WORDS cervical pedicle screw; medial angle; entry point; safe trajectory; pedicle probe; funnel-shaped hole; starting point; curved probe; surgical technique

$\mathrm{S}$ EVERAL studies have demonstrated the biomechanical superiority of cervical pedicle screw (CPS) placement. ${ }^{1,5-7,14,21}$ However, despite its biomechanical benefits, possible neurovascular complications and technical difficulties remain a great concern with this procedure. ${ }^{1,3,6,9,11,24}$
According to previous reports, including ours, most pedicle perforations occur in the lateral direction, which might cause injury to the vertebral artery (VA). ${ }^{16,23}$ These observations indicate that the most important factor during CPS placement is creating a sufficient medial angle. However, a large transverse angle of cervical pedicles leads to

\footnotetext{
ABBREVIATIONS CPS = cervical pedicle screw; Df = horizontal distance of the superior articular process; df = distance between the most medial facet point and the same sagittal facet point with the entry point of the CPS actually inserted; $D_{\text {lat }}=$ a single line on the pedicle level to connect the planned entry point to the axial middle point of the pedicle; $D_{\text {med }}=$ a line on the pedicle level to connect a medial entry point (i.e., a half-facet point) to the axial middle point of the pedicle; $\theta_{\text {ins }}=$ actual insertion angle of the pedicle screw measured on postoperative CT; $\theta_{\text {lat }}=$ angle between a vertical line and a line to connect the planned entry point and the axial middle point of the pedicle; $\theta_{\text {med }}$ = angle between a vertical line and a line to connect a new medial entry point and the axial middle point of the pedicle; VA = vertebral artery.

SUBMITTED June 23, 2016. ACCEPTED December 9, 2016.
}

INCLUDE WHEN CITING Published online May 19, 2017; DOI: 10.3171/2016.12.SPINE16738. 


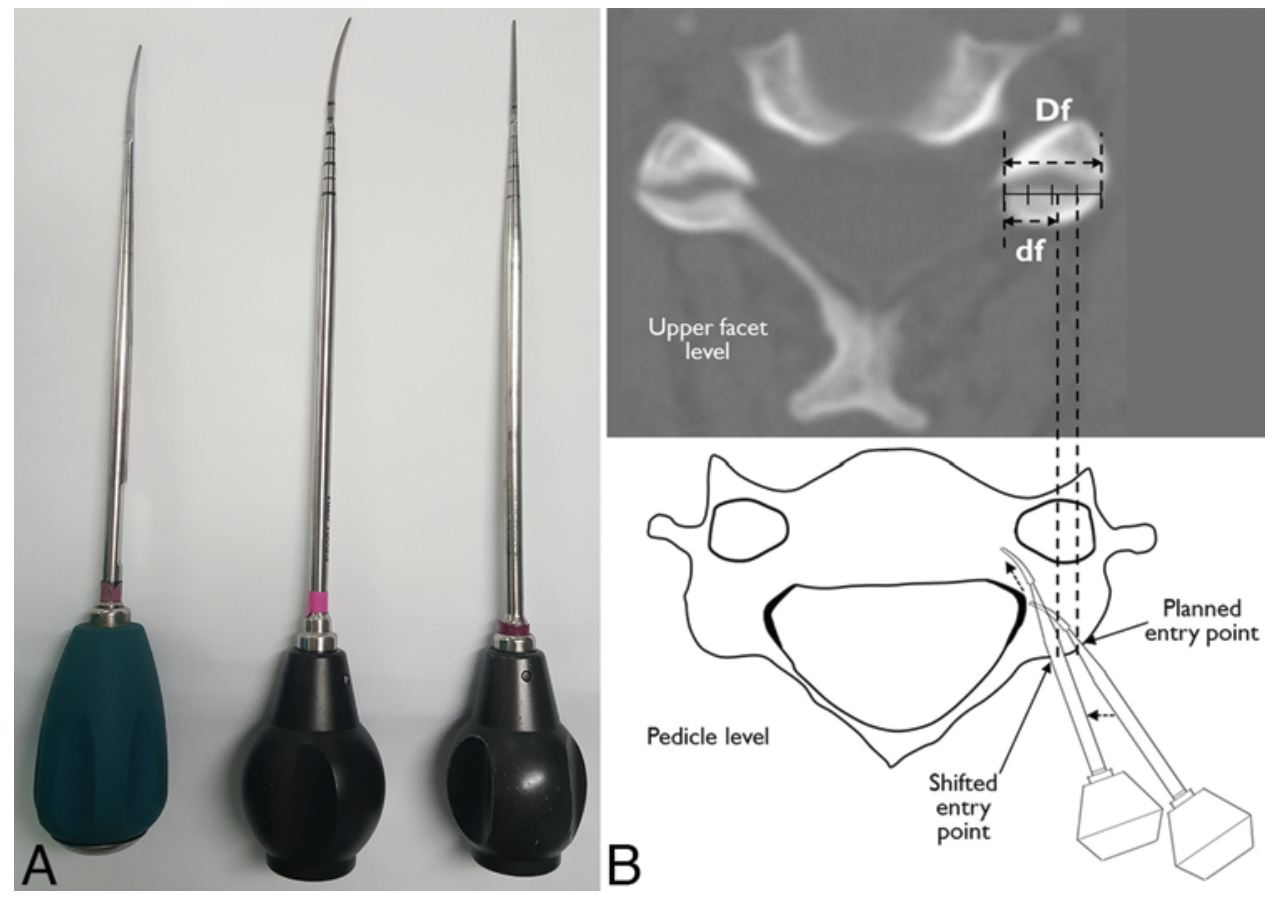

FIG. 1. A: Photographs of 3 pedicle probes. Our straight pedicle probe is shown on the right. Our curved pedicle probe in the center shows a smaller tip (i.e., $2.5 \mathrm{~mm}$ thick at the first marker, $30 \mathrm{~mm}$ from the tip) and a larger curve $\left(17^{\circ}\right)$ than the Lenke pedicle probe on the left. B: The curved pedicle probe was lodged deeply with a change in the medial angle, followed by a planned entry point that moved medially. The horizontal distance of the superior articular process included the upper facet joint (Df) on the axial CT image. The term "df" indicates the distance between the most medial facet point and the same sagittal facet point with the entry point of the CPS that was actually inserted on the postoperative axial CT image. Figure is available in color online only.

challenges in performing safe and effective CPS fixation. Thus, most spine surgeons would agree that the achievement of an anatomical cervical pedicle angle during CPS placement is extremely difficult. ${ }^{8,13,15}$ The challenges related to a small diameter of a cervical pedicle and a large transverse cervical pedicle angle have led spine surgeons to investigate how they could achieve a wider safety trajectory and reduce the insertion medial angle during CPS placement. ${ }^{1}$

Abumi et al. described the entry point location on the posterior surface of the lateral mass at the bisecting point of the width of each facet joint. A high-speed bur was used to create a funnel-shaped hole to achieve awide, safe, screw trajectory. ${ }^{1}$ However, we previously showed CPS placement could be safely performed without creating a funnelshaped hole. ${ }^{1,16,17}$ In this study, we intended to show how our CPS placement technique can increase the safety range of screw trajectory, even without a funnel-shaped hole, by using a 2.5 -mm-diameter, curved pedicle probe. In addition, we describe the other advantages of our technique.

\section{Methods}

\section{Patient Population and Surgical Technique}

From March 2012 to May 2016, a single surgeon performed posterior cervical fusion surgery using CPS placement on 119 consecutive patients (102 men, 17 women; mean age 57.7 years, range $23-83$ years). The initial diagnoses were trauma in 60 cases, degenerative disease in 48 , discitis/osteomyelitis in 4 , pathological fractures in 5 , deformity in 1 , and dumbbell tumor in 1 case. The trauma cases involved fracture and/or dislocation, and degenerative cases involved cervical spondylotic myelopathy, ossification of the posterior longitudinal ligament, or foraminal stenosis. Preoperative CT (1-mm slices) with angiography was performed in all patients. Pedicle screw insertion with a freehand technique was first considered if the outer diameter of the cervical pedicle was greater than $3.0 \mathrm{~mm}$ on axial CT.

The entry point of the screw was determined by the notch level in the sagittal plane, and was medial to the lateral border of the superior articular process, by onequarter of its width in the axial plane. However, the entry point for the C-7 vertebra was moved more medially and closer to the one-half-width point of the superior articular process in the axial plane. A small pilot hole was made at the predetermined entry point with a $1.8-\mathrm{mm}$-diameter match head-type bur. A 2.5-mm-diameter, curved pedicle probe was slowly inserted vertically to the global lamina plane with a medial trajectory through the cortical hole, and the tip was placed at the thick medial cortical pedicle wall (Fig. 1). The tip of the pedicle probe was then pushed medially, with movement in an upward and downward direction to locate the cancellous channel of the pedicle. Upon locating the cancellous channel, the medially directed force of the probe led to an insertion depth of approximately $30 \mathrm{~mm}$. After forming a track with the curved probe, a ball-tip probe palpation was performed. Next, a straight pedicle probe ( $2.5 \mathrm{~mm}$ in diameter) was inserted to make the track wider and straight. During the insertion 


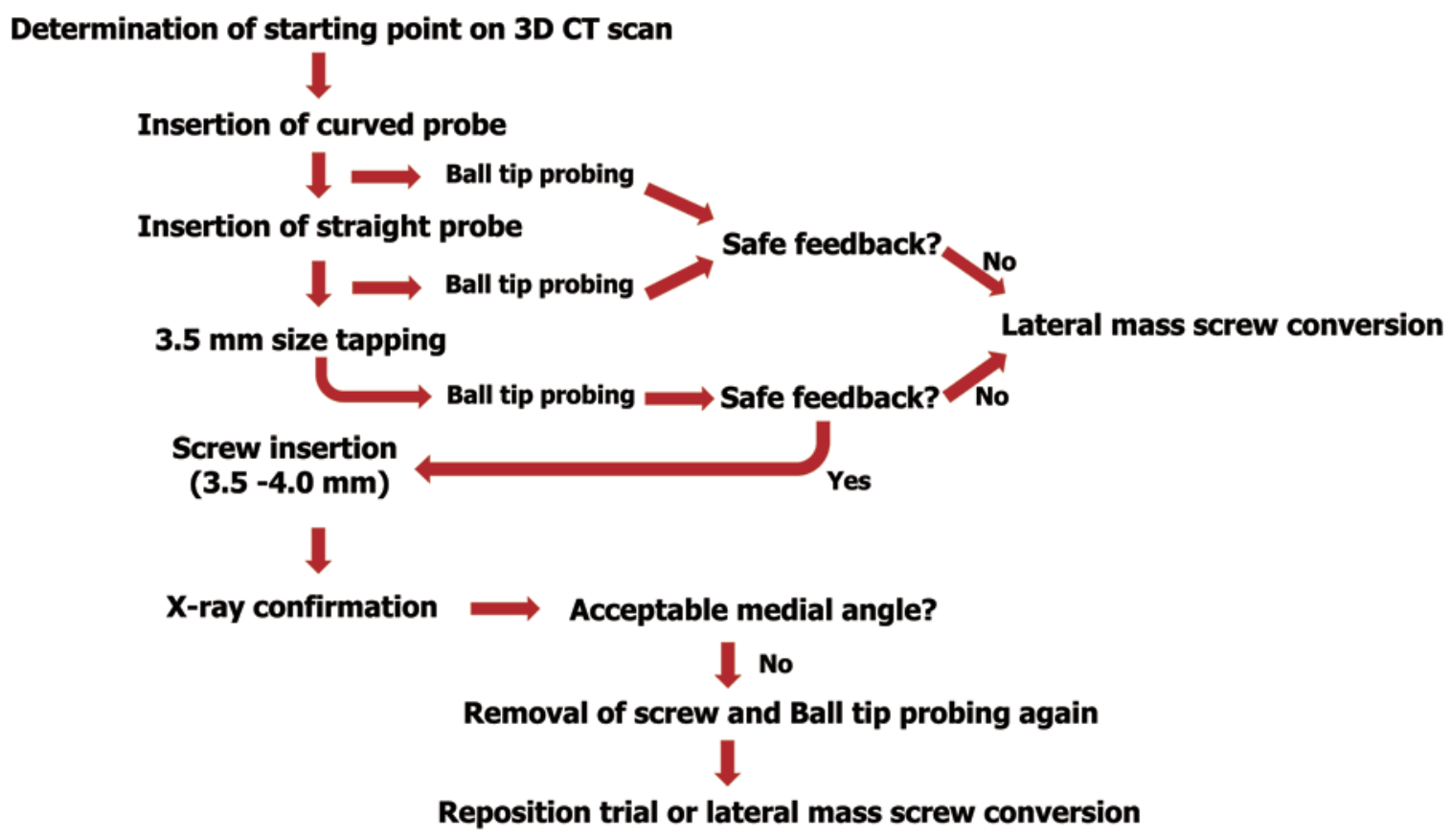

FIG. 2. A flow diagram of all processes of our CPS technique. Figure is available in color online only.

of the curved and straight pedicle probes, the entry point shifted more medially than our originally planned entry point, and the cancellous screw trajectory, including the cortical entrance, was wider (Fig. 1B). This process also increased the ease of subsequent ball-tip probe insertion, tapping, and screw placement. The depth of the ball-tip probe was measured. After tapping with a $3.5-\mathrm{mm}$-diameter tap, a screw was inserted. Screw diameter was selected according to preoperative CT measurements from the axial images. Vertex pedicle screws (Medtronic Sofamor Danek) with diameters ranging from 3.5 to $4.0 \mathrm{~mm}$ were used (Video 1).

VIDEO 1. Clip of the CPS procedure shows the widening of the safe trajectory range through shifting the entry point. Copyright Jin Hoon Park. Published with permission. Click here to view.

During the ball-tip probe palpation, sometimes feedback suggested malpositioning of the screw, which led to the abandonment of the CPS procedure and the conversion to a lateral mass screw insertion. The lateral mass screw conversion during surgery was recorded and its rate was analyzed. A more detailed description of our technique was given in our previous article. ${ }^{16}$ In addition, our technical process to ensure safety is described in a flow diagram (Fig. 2).

\section{Accuracy Analysis and the Learning Curve}

Within 5 days of surgery, postoperative CT scans in all patients were performed to identify the pedicle screw location. The breach rate in all inserted screws was analyzed using both the sagittal and axial planes. In the axial plane, lateral wall perforation was defined according to the following: Grade 1, perforation into the VA foramen with the external edge of the screw deviated out of the lateral pedicle but not violating the largest diameter of the VA foramen; Grade 2, the screw laterally deviated into the largest diameter of the VA foramen, but not completely occluding it; or Grade 3, complete occlusion of the VA foramen. ${ }^{16}$ In addition, we analyzed the screw breach rate after placement of every 100 screws to show our learning curve.

\section{Screw Insertion Angle Changes Through the Medial Shift of the Entry Point and Widening of the Trajectory}

Because our planned entry point was located relatively laterally except for C-7, our medial angle was expected to be larger and closer to the anatomical pedicle angle. ${ }^{16,23}$ However, we observed that the actually inserted CPS medial angles were smaller than expected, and exhibited more medially shifted entry points than the planned entry points on postoperative CT, such as those shown in Fig. 3. Additionally, most of the medially shifted entry points

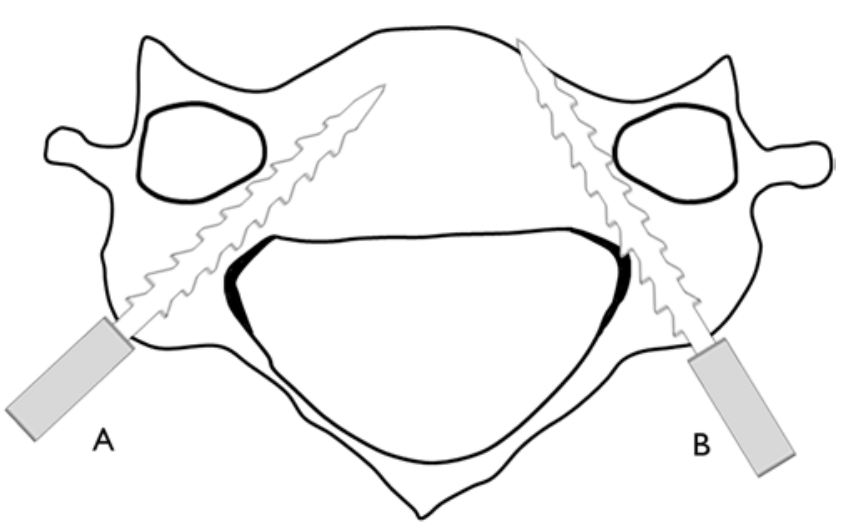

FIG. 3. A: A laterally located, planned entry point and a larger medial angle of the CPS that is close to the anatomical pedicle angle. B: Although a medially shifted entry point and smaller medial angle is visible, accurate screw positioning is observed. 


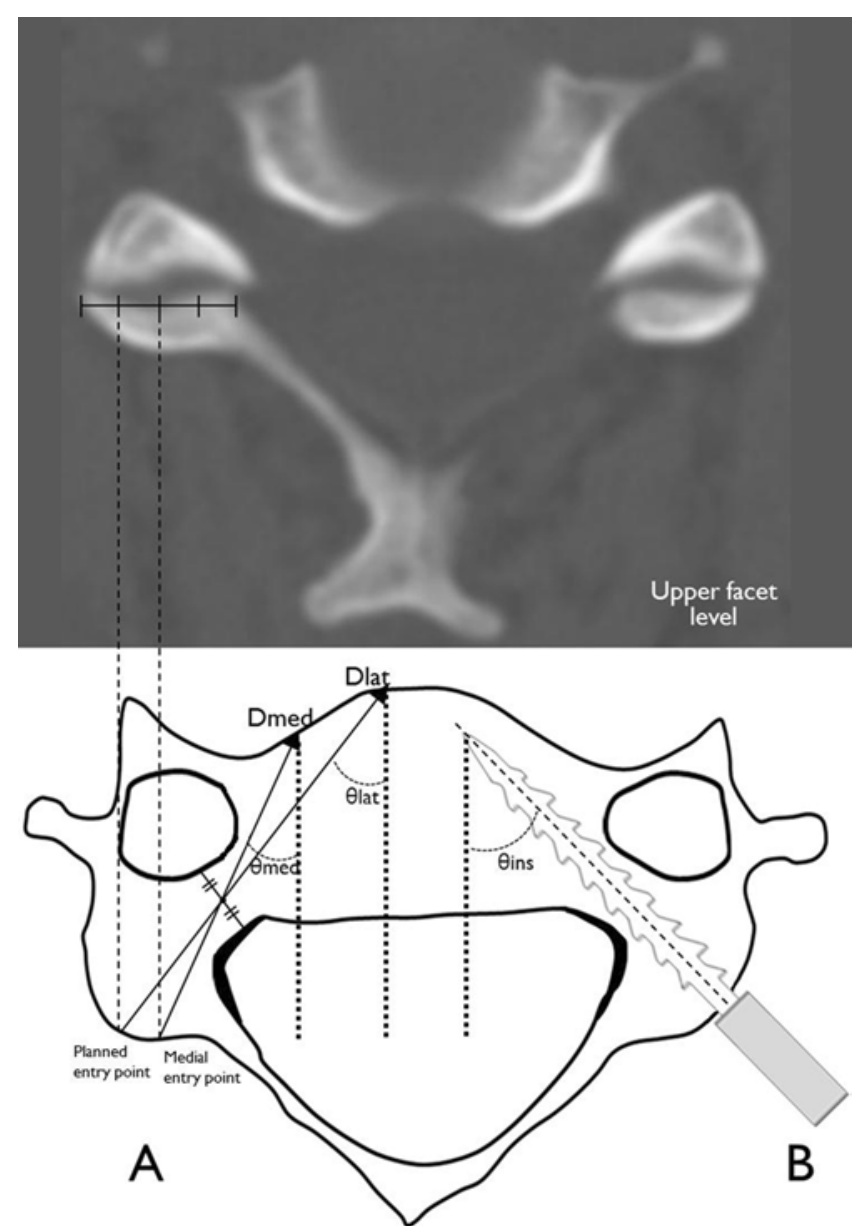

FIG. 4. A: A line, $D_{\text {lat, }}$, connected the planned entry point and the axial middle point of the pedicle, shown by preoperative axial CT. $\theta_{\text {lat }}$ was the angle between $D_{\text {lat }}$ and a vertical line to the ground. $A$ line and $D_{\text {med }}$ connect a new medial entry point and the axial middle point of the pedicle. $\theta_{\text {med }}$ was the angle between $D_{\text {med }}$ and a vertical line to the ground. B: $\theta_{\text {ins }}$ was a medial angle of the actually inserted CPS as assessed by postoperative $\mathrm{CT}$.

did not cross the bisecting point of the width of each facet joint. Our present study was initiated based on these findings and aimed to identify and compare the planned medial angles that were closer to the anatomical pedicle angle and the actual insertion medial angles, which were smaller because of medial shifting of the entry point and trajectory widening.

First, we drew a single line $\left(\mathrm{D}_{\text {lat }}\right)$ on the pedicle level to connect our planned entry point-which is the same sagittal location as the upper facet point, medial to the lateral border of the superior articular process by one-quarter of its width in the axial plane-to the axial middle point of the pedicle on the preoperative axial CT image. We measured an angle $\left(\theta_{\text {lat }}\right)$ between $D_{\text {lat }}$ and a vertical line to the ground. Then, we drew another line $\left(\mathrm{D}_{\text {med }}\right)$ on the pedicle level to connect a new medial entry point-which was the same sagittal location as the upper facet point, medial to the lateral border of the superior articular process by onehalf of its width in the axial plane-to the axial middle point of the pedicle. We also measured the angle $\left(\theta_{\text {med }}\right)$ between $\mathrm{D}_{\text {med }}$ and a vertical line to the ground (Fig. 4A). If the distance of $D_{\text {med }}$ was less than $26 \mathrm{~mm}$, which we regarded as a minimally acceptable screw length without perforation of the anterior cortex, we moved above the new medial entry point slightly to the lateral side and then drew the $\mathrm{D}_{\text {med }}$ again. In addition, we measured the actual insertion angle of the pedicle screw $\left(\theta_{\text {ins }}\right)$ using a postoperative CT scan (Fig. 4B). All of the above variable measurements were performed only on an accurately located CPS. To identify how much medial angle on the $\theta_{\text {ins }}$ could be reduced from the anatomical pedicle angle $\left(\theta_{\text {lat }}\right)$ and how much closer to the $\theta_{\text {med }}$, we calculated $\left(\theta_{\text {ins }}-\theta_{\text {med }}\right) /\left(\theta_{\text {lat }}{ }^{-}\right.$ $\left.\theta_{\text {med }}\right)$ in all accurately located CPSs.

To verify entry point shifting and trajectory widening, we measured the horizontal distance of the superior articular process that constituted the upper facet joint (Df) on the axial CT image. Additionally, df was calculated as the distance between the most medial facet point and the same sagittal facet point, with the entry point of the actual inserted CPS on the axial CT image. The mean df/Df values in all cervical levels were analyzed (Fig. 1B).

\section{Results}

None of the patients showed symptoms related to VA injury, VA stenosis, or root compression. There were 4 revisions, including those for 3 patients with wound infection and 1 for a patient with distal-level screw fracture resulting in pseudarthrosis. There were 2 patients with temporary C-5 palsy, but revision was not necessary. The total number of planned CPSs was 759, and lateral mass screw conversion occurred for 35 screws $(4,13,11$, and 5 on C-3, C-4, C-5, and C-6, respectively), as well as 2 conversions to a laminar screw on C-7. Thus, the conversion rate was $4.61 \%$ (35/759) and the total number of actually inserted CPSs was $724(94,134,169,189$, and 138 on C37 , respectively). A total of 25 lateral wall violations constituted 20 Grade I $(0,7,7,3$, and 3 on C3-7) and 5 Grade 2 violations $(0,2,1,1$, and 1 on C3-7). There were 2 inferior wall violations on the C-3 and C-7 levels and 3 medial wall violations (i.e., 1 on C-5 and 2 on C-6 levels; Table 1 ). The overall accuracy rate was $95.9 \%$ (694/724), and the results were slightly improved compared with those we reported previously. ${ }^{16}$ Our learning curve showed that the majority of misplacement occurred before 100 screws, but it plateaued after 100 screws (Fig. 5).

The mean \pm SD $\theta_{\text {lat }}$ values were $41.6^{\circ} \pm 4.31^{\circ}, 40.8^{\circ} \pm$ $3.32^{\circ}, 38.3^{\circ} \pm 3.84^{\circ}, 36.5^{\circ} \pm 3.38^{\circ}$, and $28.6^{\circ} \pm 4.29^{\circ}$ on the C3-7 levels, respectively. The mean $\theta_{\text {med }}$ values were $28.3^{\circ}$ $\pm 3.51^{\circ}, 29.4^{\circ} \pm 3.67^{\circ}, 27.4^{\circ} \pm 3.97^{\circ}, 25.8^{\circ} \pm 4.12^{\circ}$, and $21.9^{\circ}$ $\pm 3.59^{\circ}$ on the $\mathrm{C} 3-7$ levels. The mean $\theta_{\text {ins }}$ values were $37.1^{\circ}$ $\pm 4.31^{\circ}, 33.3^{\circ} \pm 4.59^{\circ}, 31.3^{\circ} \pm 4.97^{\circ}, 30.1^{\circ} \pm 5.14^{\circ}$, and $31.2^{\circ}$ $\pm 6.38^{\circ}$ on the C3-7 levels (Fig. 6A). The mean df/Df values were $0.64,0.62,0.63,0.63$, and 1.24 on the C3-7 levels. The mean $\left(\theta_{\text {ins }}-\theta_{\text {med }}\right) /\left(\theta_{\text {lat }}-\theta_{\text {med }}\right)$ values were $0.85,0.78$, $0.77,0.78$, and 1.11 on the C3-7 levels (Fig. 6B). Thus, we could calculate that $\theta_{\text {ins }}$ could be expected near the $90 \%$ value of $\theta_{\text {lat }}$ on the C-3 level from the equation of $\theta_{\text {ins }}=$ $0.85 \theta_{\text {lat }}+0.15 \theta_{\text {med }}$ approximately equal to $0.9 \theta_{\text {lat }}$. Similarly, $80 \%, 80 \%, 80 \%$, and $110 \%$ values of $\theta_{\text {lat }}$ on the $\mathrm{C} 4-7$ levels can be expected. 
TABLE 1. The number of planned CPSs with conversion and accuracy rates

\begin{tabular}{|c|c|c|c|c|c|c|c|}
\hline \multirow{2}{*}{$\begin{array}{c}\text { Cervical } \\
\text { Level }\end{array}$} & \multirow{2}{*}{$\begin{array}{l}\text { Planned } \\
\text { CPSs }\end{array}$} & \multirow{2}{*}{$\begin{array}{l}\text { No. Converted Into } \\
\text { Lat Mass Screws (\%) }\end{array}$} & \multirow{2}{*}{$\begin{array}{c}\text { No. of CPSs } \\
\text { Actually Inserted }\end{array}$} & \multicolumn{2}{|c|}{ Lat Wall Perforation } & \multirow{2}{*}{$\begin{array}{c}\text { Inferior/Medial } \\
\text { Wall Perforations }\end{array}$} & \multirow{2}{*}{$\begin{array}{l}\text { Accuracy } \\
\text { Rate (\%) }\end{array}$} \\
\hline & & & & Grade 1 & Grade 2 & & \\
\hline C-3 & 98 & $4(4.1)$ & 94 & 0 & 0 & 1 (inferior) & 98.9 \\
\hline C-4 & 147 & $13(8.8)$ & 134 & 7 & 2 & 0 & 93.3 \\
\hline$C-5$ & 180 & $11(6.1)$ & 169 & 7 & 1 & 1 (medial) & 94.7 \\
\hline $\mathrm{C}-6$ & 194 & $5(2.6)$ & 189 & 3 & 1 & 2 (medial) & 96.8 \\
\hline C-7 & 140 & $2(1.4)$ & 138 & 3 & 1 & 1 (inferior) & 96.4 \\
\hline Total & 759 & $35(4.61)$ & 724 & 20 & 5 & 5 & 95.9 \\
\hline
\end{tabular}

\section{Discussion}

The biomechanical superiority of CPS compared with other modes of fixation, such as lateral mass screws, has been described..$^{1,5-7,14,21}$ Its advantage regarding strong fixation power, especially in deformity, tumor, or trauma, has been reported. ${ }^{1,2,16,17,19,20,25}$

However, despite these biomechanical benefits, the small diameter and large transverse angle of cervical pedicles lead to challenges regarding possible neurovascular complications in performing safe and effective CPS placement. ${ }^{1,8,13,15,16}$ These concerns led us to develop our technique to find cancellous tracks safely in the small pedicle and reduce the necessary medial angle.

It is well known that if an entry point is located more laterally, the medial angle of the CPS may be greater and closer to the anatomical pedicle angle., ${ }^{1,23}$ Abumi et al. recommended the creation of a funnel-shaped hole to yield a wider-ranged zone of safe medial angles, despite having a potentially smaller length of the CPS (Fig. 7A). It also enables a surgeon to use the entry point at the bisecting point of the width of each facet joint, and to perform the safe CPS placement with a small medial angle ranging from $25^{\circ}$ to $45^{\circ}$, but with a small-length screw that does not exceed $22 \mathrm{~mm} .{ }^{1,16,23}$

Our planned entry point was medial to the lateral border of the superior articular process by one-quarter of its width in the axial plane, except in the C-7 vertebrae. ${ }^{16}$ The mean values of df/Df in Fig. 6B show that most of our planned entry points shifted medially, because we planned to use an entry point at the medial to lateral border of the superior articular process by a quarter of its width in the axial plane (i.e., $\mathrm{df} / \mathrm{Df}=0.75$ ), except at the $\mathrm{C}-7$ vertebrae. Through gradually wider and straighter instrument insertion, such as with a straight pedicle probe, tapper, and screw after a curved pedicle probe insertion that might result in entry point shift (Fig. 1B), the initial pilot hole and track are widened and straightened. We believe that the medial shift of the planned entry point and the decreased medial angle occur simultaneously during the widening and straightening of the pilot hole and cancellous pedicle track. This means that a medially shifted entry point can also yield a wider-ranged angle zone for safe CPS placement despite a planned entry point that was located laterally, even without creating a funnel-shaped hole (Fig. 7B). Thus, this shifting of the entry point also enables the $\theta_{\text {ins }}$ to be smaller than $\theta_{\text {lat }}$ on the C3-6 levels (Fig. 3B). Because it is extremely difficult to achieve a medial angle with the same anatomical cervical pedicle medial angle, ${ }^{4,8,12,13,15,22}$ entry point shifting can not only provide us with a widerranged angle zone (i.e., safe trajectory widening) for safe CPS placement (Fig. 7B), but it can also result in safe CPS placement, even with a smaller medial angle than the anatomical pedicle angle (Fig. 3B). We believe that entry point shifting is a natural process if every surgeon uses a curved pedicle probe and attempts to achieve a safe medial angle despite the absence of effort to create a funnelshaped hole.

We showed that the mean $\left(\theta_{\text {ins }}-\theta_{\text {med }}\right) /\left(\theta_{\text {lat }}-\theta_{\text {med }}\right)$ values were $0.85,0.78,0.77,0.78$, and 1.11 on the $\mathrm{C} 3-7$ levels, respectively. We can draw a reverse calculation from the above equation as $\theta_{\text {ins }}=0.85 \theta_{\text {lat }}+0.15 \theta_{\text {med }}$ on the C-3 level. Because $\theta_{\text {med }}$ values in all the levels range from $20^{\circ}$ to $30^{\circ}, 0.15 \theta_{\text {med }}$ can range from $3.0^{\circ}$ to $4.5^{\circ}$. This means that $\theta_{\text {ins }}$ on the C-3 level can range from $0.85 \theta_{\text {lat }}+3.0^{\circ}$ to $0.85 \theta_{\text {lat }}+4.5^{\circ}$. In other words, $\theta_{\text {ins }}$ could be expected near the $90 \%$ value of $\theta_{\text {lat }}$ on the C-3 level. Similarly, $80 \%, 80 \%$, $80 \%$, and $110 \%$ values of $\theta_{\text {lat }}$ on C-4, C-5, C-6, and C-7 levels can be expected. This result suggests that we can reduce the necessary safe medial angle compared with the burdensome anatomical cervical pedicle lateral angle by using our curved probe and laterally located starting point, followed by an entry point shift and trajectory widening, even without a funnel-shaped hole.

Considering the entry point shift of $0.64,0.62,0.63$, 0.63 , and 1.24 on the $\mathrm{C} 3-7$ levels, and the $\theta_{\text {ins }} 90 \%, 80 \%$, $80 \%, 80 \%$, and $110 \% \theta_{\text {lat }}$ on the C3-7 levels, we can explain that a similar entry point shift resulted in a similarly decreased medial angle on the C-3, C-4, C-5, and C-6 levels. Because we selected a more medial entry point (halffacet point) on C-7, and considering a large C-7 pedicle size, an entry point lateral shift could occur, resulting in

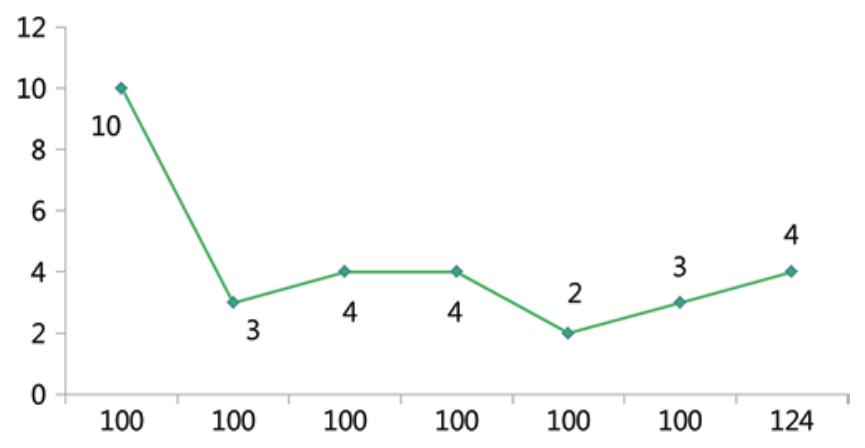

FIG. 5. A graph of the CPS technique learning curve showing the number of misplaced screws ( $y$-axis) per every 100 screws ( $x$-axis). Figure is available in color online only. 


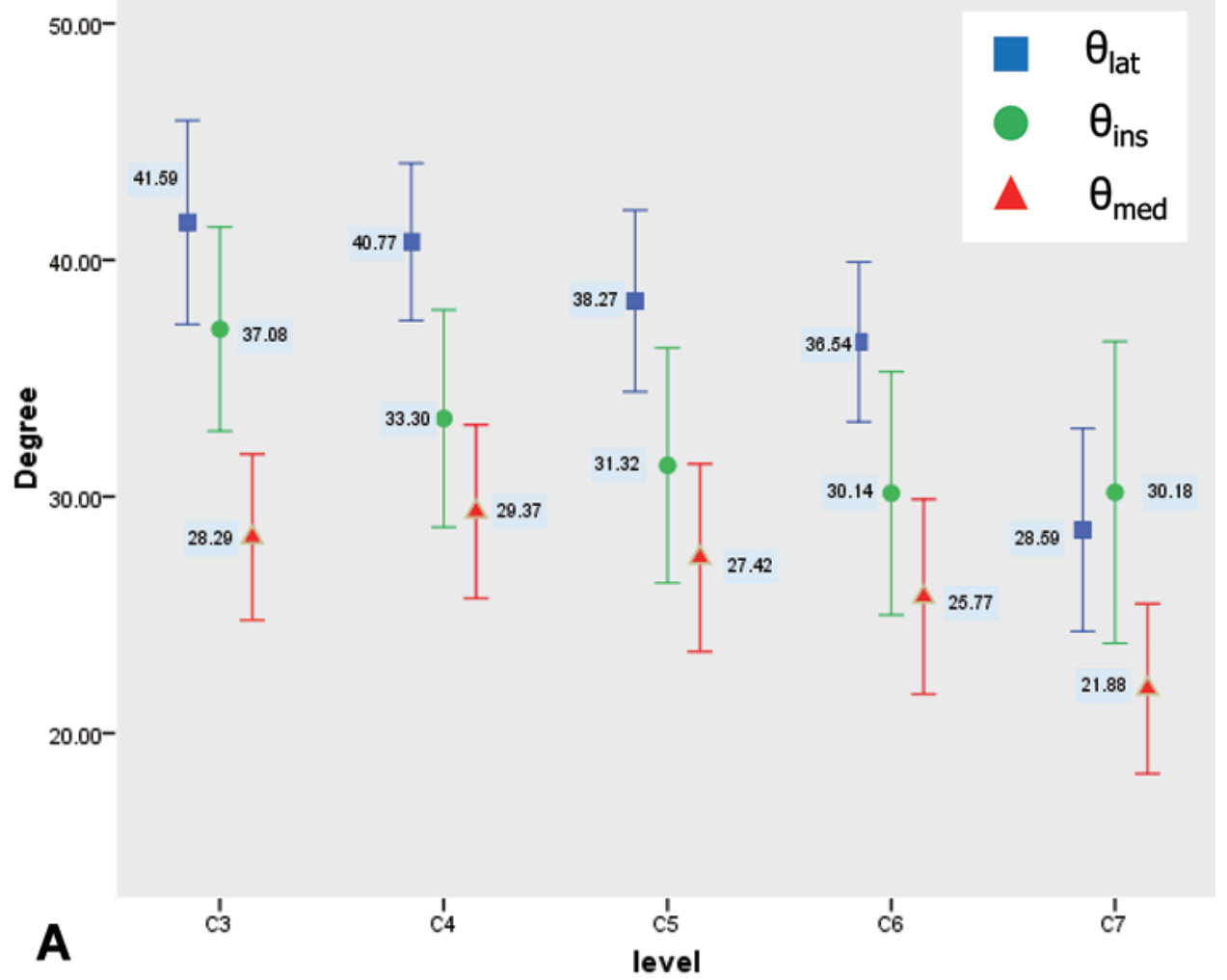

$2.00-$

\section{$\mathrm{df} / \mathrm{Df}$}

$\left(\theta_{\text {ins }}-\theta_{\text {med }}\right) /\left(\theta_{\text {lat }}-\theta_{\text {med }}\right)$

$1.50-$

$1.00^{-}$
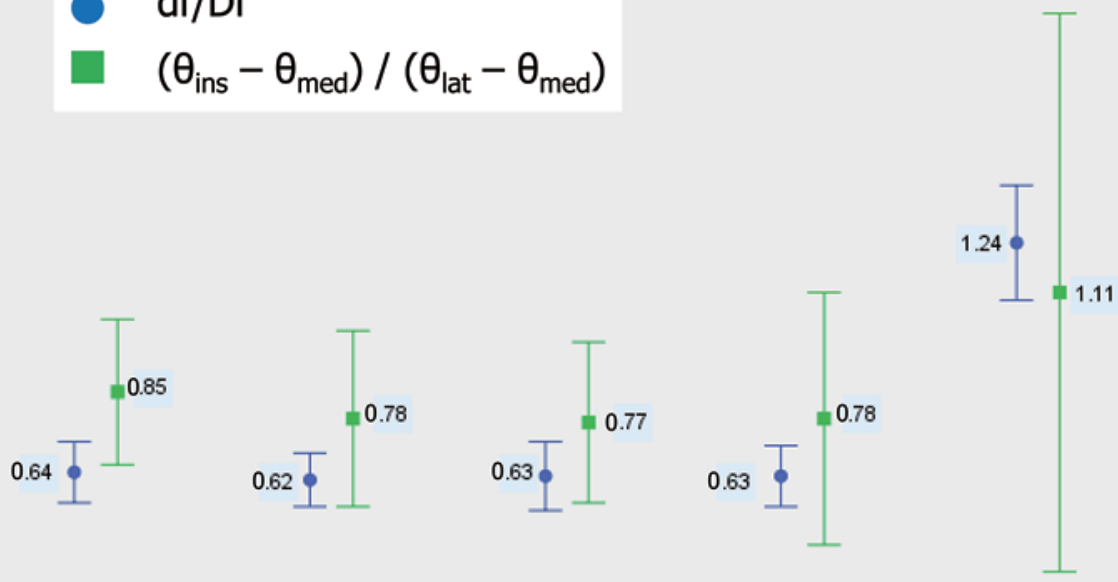

$0.00^{-}$

B

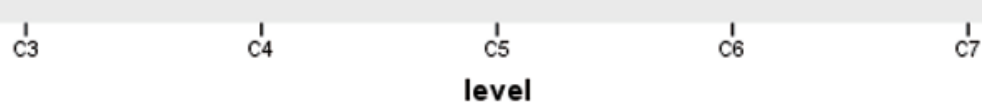

FIG. 6. A: A graph of $\theta_{\text {lat }}, \theta_{\text {ins }}$, and $\theta_{\text {med }}$ degrees in accurately located screws. The mean values of $\theta_{\text {ins }}$ are between the mean values of $\theta_{\text {lat }}$ and $\theta_{\text {med }}$ from the C-3 to the C- 6 levels. This means we can reduce the required medial angle safely. An error bar indicates standard deviation. B: A graph of df/Df and $\left(\theta_{\text {ins }}-\theta_{\text {med }}\right) /\left(\theta_{\text {lat }}-\theta_{\text {med }}\right)$ values in accurately located screws. The mean values of $\mathrm{df} / \mathrm{Df}$ are between 0.62 and 0.64 , which are less than 0.75 (planned entry point) from the C-3 to the C-6 levels. The value of the C-7 level is 1.24. Thus, this means that the entry point can be shifted medially from the C-3 to the C- 6 levels and that of the C-7 level occurred laterally. According to $\left(\theta_{\text {ins }}-\theta_{\text {med }}\right) /\left(\theta_{\text {lat }}-\theta_{\text {med }}\right)$ values, we can calculate that the mean $\theta_{\text {ins }}$ is similar to $90 \%, 80 \%$, $80 \%, 80 \%$, and $110 \%$ of $\theta_{\text {lat }}$. An error bar indicates standard deviation. Figure is available in color online only. 


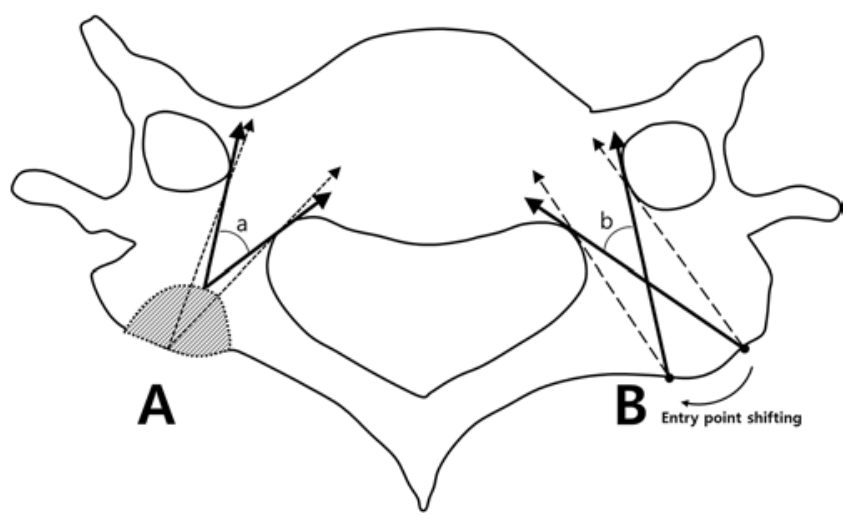

FIG. 7. Schematic drawing of the safe zone for the medial angle (A), in which a funnel-shaped hole can provide a wider-ranged zone (a) for a safe medial angle. Entry point shifting (B) can also provide a widerranged zone (b) for a safe medial angle.

a larger medial angle than the anatomical lateral pedicle angle on C-7 vertebrae (Fig. 6).

Our CPS technique has several advantages compared with that of Abumi et al. ${ }^{1,16,23}$ Because we do not create a funnel-shaped hole on the cervical lateral mass, we can use a longer screw (i.e., usually $30 \mathrm{~mm}$ ), have a longer bone and screw engagement, and reduce surgical time. In addition, we believe that lateral mass screw conversion (4.61\%) during CPS placement is an important safety step if the ball-tip feedback is not ideal. However, the creation of a funnel-shaped hole eliminates the possibility of a lateral mass screw conversion. If we believed that the ball-tip feedback was not inside the bone at any step in the procedure, or if the radiographic identification of screw position was not ideal, a lateral mass screw conversion was easily performed ${ }^{16}$ In addition, for the safety of the patient, there were no more than 2 or 3 attempts at inserting the curved probe before the conversion to a lateral mass screw placement.

Because we selected patients whose axial pedicle size was greater than $3 \mathrm{~mm}$ and had no VA anomaly for the CPS placement, ${ }^{16}$ we believe that small pedicle size and VA anomaly were not the main cause of the lateral mass screw conversion. In patients whose individual pedicle on a CT scan showed an almost sclerotic bone and a lack of a cancellous track, we had some difficulties with our CPS technique; thus, these cases resulted in many lateral mass screw conversions.

Insertion of pedicle screws into cervical vertebrae, despite using a freehand technique, may thus be safe and effective if adequate training is provided, similar to what surgeons undergo for thoracolumbar levels..$^{10,18,23}$ In addition to our learning curve (Fig. 5), the training experience of the surgeon who performed all cases in this study can be summarized as follows. After extensive fellowship training, including 1 complete year of training in the placement of freehand thoracolumbar pedicle screws, he also established his freehand technique in CPS insertion by practicing on 5 cadavers. He then began his own practice of this CPS technique and maintained the safety process as described in the flow diagram (Fig. 2) and treated 119 patients for 4.2 years without any neurovascular complications. In ad- dition to maintaining the safety process, we believe that the curved pedicle probe and lateral mass screw conversion helped us to avoid such complications and perform safe CPS procedures from an early stage.

\section{Conclusions}

Through the use of the curved pedicle probe and a laterally located starting point, the planned and laterally located entry point medial shift occurred during CPS placement. This entry point shift yielded a wider, safe trajectory and reduced the burden of making a large medial angle, similar to the anatomical cervical pedicle lateral angle, for safe CPS placement without creating a funnel-shaped hole. The absence of funnel-shaped hole creation during CPS placement allows us to use a longer screw, have a longer bone and screw engagement, reduce surgical time, and easily convert the procedure into lateral mass screw placement.

\section{Acknowledgments}

We thank Seung Geun Lee, Medical Information Technology Team, Gangneung Asan Hospital, for creating the video of our CPS procedure.

\section{References}

1. Abumi K, Ito M, Sudo H: Reconstruction of the subaxial cervical spine using pedicle screw instrumentation. Spine (Phila Pa 1976) 37:E349-E356, 2012

2. Abumi K, Itoh H, Taneichi H, Kaneda K: Transpedicular screw fixation for traumatic lesions of the middle and lower cervical spine: description of the techniques and preliminary report. J Spinal Disord 7:19-28, 1994

3. Abumi K, Shono Y, Ito M, Taneichi H, Kotani Y, Kaneda $\mathrm{K}$ : Complications of pedicle screw fixation in reconstructive surgery of the cervical spine. Spine (Phila Pa 1976) 25:962 969,2000

4. Chazono M, Soshi S, Inoue T, Kida Y, Ushiku C: Anatomical considerations for cervical pedicle screw insertion: the use of multiplanar computerized tomography reconstruction measurements. J Neurosurg Spine 4:472-477, 2006

5. Hong JT, Qasim M, Espinoza Orías AA, Natarajan RN, An HS: A biomechanical comparison of three different posterior fixation constructs used for C6-C7 cervical spine immobilization: a finite element study. Neurol Med Chir (Tokyo) 54:727-735, 2014

6. Johnston TL, Karaikovic EE, Lautenschlager EP, Marcu D: Cervical pedicle screws vs. lateral mass screws: uniplanar fatigue analysis and residual pullout strengths. Spine J 6:667-672, 2006

7. Jones EL, Heller JG, Silcox DH, Hutton WC: Cervical pedicle screws versus lateral mass screws. Anatomic feasibility and biomechanical comparison. Spine (Phila Pa 1976) 22:977-982, 1997

8. Karaikovic EE, Daubs MD, Madsen RW, Gaines RW Jr: Morphologic characteristics of human cervical pedicles. Spine (Phila Pa 1976) 22:493-500, 1997

9. Kast E, Mohr K, Richter HP, Börm W: Complications of transpedicular screw fixation in the cervical spine. Eur Spine J 15:327-334, 2006

10. Kim YJ, Lenke LG, Bridwell KH, Cho YS, Riew KD: Free hand pedicle screw placement in the thoracic spine: is it safe? Spine (Phila Pa 1976) 29:333-342, 2004

11. Kotani Y, Abumi K, Ito M, Minami A: Improved accuracy of computer-assisted cervical pedicle screw insertion. J Neurosurg 99 (3 Suppl):257-263, 2003 
12. Liu J, Napolitano JT, Ebraheim NA: Systematic review of cervical pedicle dimensions and projections. Spine (Phila Pa 1976) 35:E1373-E1380, 2010

13. Ludwig SC, Kramer DL, Vaccaro AR, Albert TJ: Transpedicle screw fixation of the cervical spine. Clin Orthop Relat Res (359):77-88, 1999

14. McGirt MJ, Sutter EG, Xu R, Sciubba DM, Wolinsky JP, Witham TF, et al: Biomechanical comparison of translaminar versus pedicle screws at $\mathrm{T} 1$ and $\mathrm{T} 2$ in long subaxial cervical constructs. Neurosurgery 65 (6 Suppl):167-172, 2009

15. Panjabi MM, Shin EK, Chen NC, Wang JL: Internal morphology of human cervical pedicles. Spine (Phila Pa 1976) 25:1197-1205, 2000

16. Park JH, Jeon SR, Roh SW, Kim JH, Rhim SC: The safety and accuracy of freehand pedicle screw placement in the subaxial cervical spine: a series of 45 consecutive patients. Spine (Phila Pa 1976) 39:280-285, 2014

17. Park JH, Roh SW, Rhim SC: A single-stage posterior approach with open reduction and pedicle screw fixation in subaxial cervical facet dislocations. J Neurosurg Spine 23:35-41, 2015

18. Parker SL, McGirt MJ, Farber SH, Amin AG, Rick AM, Suk I, et al: Accuracy of free-hand pedicle screws in the thoracic and lumbar spine: analysis of 6816 consecutive screws. Neurosurgery 68: 170-178, 2011

19. Rajasekaran S, Kanna PR, Shetty AP: Safety of cervical pedicle screw insertion in children: a clinicoradiological evaluation of computer-assisted insertion of 51 cervical pedicle screws including 28 subaxial pedicle screws in 16 children. Spine (Phila Pa 1976) 37:E216-E223, 2012

20. Rajasekaran S, Kanna PR, Shetty TA: Intra-operative computer navigation guided cervical pedicle screw insertion in thirty-three complex cervical spine deformities. J Craniovertebr Junction Spine 1:38-43, 2010

21. Rhee JM, Kraiwattanapong C, Hutton WC: A comparison of pedicle and lateral mass screw construct stiffnesses at the cervicothoracic junction: a biomechanical study. Spine (Phila Pa 1976) 30:E636-E640, 2005

22. Sakamoto T, Neo M, Nakamura T: Transpedicular screw placement evaluated by axial computed tomography of the cervical pedicle. Spine (Phila Pa 1976) 29:2510-2515, 2004
23. Yoshimoto H, Sato S, Hyakumachi T, Yanagibashi Y, Kanno T, Masuda T: Clinical accuracy of cervical pedicle screw insertion using lateral fluoroscopy: a radiographic analysis of the learning curve. Eur Spine J 18:1326-1334, 2009

24. Yoshimoto H, Sato S, Hyakumachi T, Yanagibashi Y, Masuda T: Spinal reconstruction using a cervical pedicle screw system. Clin Orthop Relat Res (431):111-119, 2005

25. Yukawa Y, Kato F, Yoshihara H, Yanase M, Ito K: Cervical pedicle screw fixation in 100 cases of unstable cervical injuries: pedicle axis views obtained using fluoroscopy. J Neurosurg Spine 5:488-493, 2006

\section{Disclosures}

The authors report no conflict of interest concerning the materials or methods used in this study or the findings specified in this paper.

\section{Author Contributions}

Conception and design: Park. Acquisition of data: Park, S Lee, Seo, MK Lee. Analysis and interpretation of data: Park, S Lee. Drafting the article: Park, Seo, MK Lee. Critically revising the article: Park, S Lee. Reviewed submitted version of manuscript: Park, Jeon, Roh, Rhim. Approved the final version of the manuscript on behalf of all authors: Park. Statistical analysis: Park. Administrative/technical/material support: Park. Study supervision: Park.

\section{Supplemental Information \\ Videos}

Video 1. https://vimeo.com/200017894.

\section{Correspondence}

Jin Hoon Park, Department of Neurological Surgery, Gangneung Asan Hospital, University of Ulsan College of Medicine, 36, Bangdong-gil, Sacheon-myeon, Gangneung-si, Gangwon-do 25440, Korea. email: grandblue@gnah.co.kr. 